Louisiana State University

LSU Digital Commons

Faculty Publications

Department of Biological Sciences

$12-1-2018$

\title{
Homogenization of species composition and species association networks are decoupled
}

\author{
Daijiang Li \\ University of Florida \\ Timothée Poisot \\ University of Montreal \\ Donald M. Waller \\ University of Wisconsin-Madison \\ Benjamin Baiser \\ University of Florida
}

Follow this and additional works at: https://digitalcommons.Isu.edu/biosci_pubs

\section{Recommended Citation}

Li, D., Poisot, T., Waller, D., \& Baiser, B. (2018). Homogenization of species composition and species association networks are decoupled. Global Ecology and Biogeography, 27 (12), 1481-1491.

https://doi.org/10.1111/geb.12825

This Article is brought to you for free and open access by the Department of Biological Sciences at LSU Digital Commons. It has been accepted for inclusion in Faculty Publications by an authorized administrator of LSU Digital Commons. For more information, please contact ir@lsu.edu. 


\section{Homogenization of species composition and species association networks are decoupled}

\section{Daijiang Li ${ }^{1}$ (D) | Timothée Poisot ${ }^{2}$ (D) | Donald M. Waller ${ }^{3}$ | Benjamin Baiser ${ }^{1}$ (C)}

\author{
${ }^{1}$ Department of Wildlife Ecology and \\ Conservation, University of Florida, \\ Gainesville, Florida \\ ${ }^{2}$ Département de Sciences \\ Biologiques, Université de Montréal, \\ Montréal, Québec, Canada \\ ${ }^{3}$ Department of Botany, University of \\ Wisconsin-Madison, Madison, Wisconsin
}

\section{Correspondence}

Daijiang Li, Department of Wildlife Ecology and Conservation, University of Florida,

Gainesville, FL 32611.

Email: daijianglee@gmail.com

Funding information

NSF, Grant/Award Number: ABI 1458034 and DEB 1046355

\begin{abstract}
Aim: Ecological communities are composed of both species and the biotic relationships (interactions or spatial associations) among them. Biotic homogenization in species composition (i.e., increased site-to-site similarity) is recognized as a common consequence of global change, but less is known about how the similarity of species relationships changes over space and time. Does homogenization of species composition lead to homogenization of species relationships or are the dynamics of species relationships decoupled from changes in species composition?

Location: Wisconsin, USA.

Time period: $1950-2012$.

Major taxa studied: Vascular plants.

Methods: We used long-term resurvey data to analyse changes in plant species association patterns between the 1950s and 2000s at 266 sites distributed among three community types in Wisconsin, USA. We used species associations (quantified via local co-occurrence patterns) to represent one type of relationship among species. Species pairs that co-occur more or less than expected by chance have positive or negative associations, respectively. We then measured beta diversity in both species composition and species association networks over time and space.

Results: Shifts in species associations consistently exceeded the shifts observed in species composition. Less disturbed forests of northern Wisconsin have converged somewhat in species composition but little in species associations. In contrast, forests in central Wisconsin succeeding from pine barrens to closed-canopy forests have strongly homogenized in both species composition and species associations. More fragmented forests in southern Wisconsin also tended to converge in species composition and in the species' negative associations, but their positive associations diverged over the last half century. Species composition and associations are generally affected by a similar set of environmental variables. Their relative importance, however, has changed over time.

Main conclusions: Long-term shifts in species relationships appear to be decoupled from shifts in species composition despite being affected by similar environmental variables.
\end{abstract}

\section{KEYWORDS}

beta diversity, long-term changes, networks, species composition, species co-occurrence, species interactions 


\section{1 | INTRODUCTION}

Global environmental changes, including shifts in climate, land use and management and species invasions, are affecting many communities and ecosystems (Sala et al., 2000; Vitousek, Mooney, Lubchenco, \& Melillo, 1997) and forming novel ecosystems (Hobbs, Higgs, \& Harris, 2009). One consequence of this human-induced biotic upheaval is biotic homogenization $(\mathrm{BH})$, the increase in compositional similarity of spatially distinct ecological assemblages (i.e., decline in beta diversity; McKinney \& Lockwood, 1999; Olden, Comte, \& Giam, 2018; Olden \& Poff, 2003). Biotic homogenization has been documented in several ecosystems, taxonomic groups and spatial scales (e.g., Baiser, Olden, Record, Lockwood, \& McKinney, 2012; Li \& Waller, 2015; Rooney, Wiegmann, Rogers, \& Waller, 2004; de Solar et al., 2015). Such declines in beta diversity can adversely affect ecosystem functions (Olden, Poff, Douglas, Douglas, $\&$ Fausch, 2004) by reducing ecosystem services "insurance" effects (Loreau, Mouquet, \& Gonzalez, 2003).

Environmental changes can also modify relationships among species (e.g., biotic interactions, spatial associations; Blois, Zarnetske, Fitzpatrick, \& Finnegan, 2013; Tylianakis, Didham, Bascompte, \& Wardle, 2008). This may result in new predator-prey interactions (Rockwell, Gormezano, \& Koons, 2011), intensified predation (Harley, 2011), changes in plant phenology leading to pollination mismatches (Hegland, Nielsen, Lázaro, Bjerknes, \& Totland, 2009), and changes in non-trophic relationships among species, such as species spatial association (Li \& Waller, 2016; Milazzo, Mirto, Domenici, \& Gristina, 2013). Species relationships may in fact be more sensitive and susceptible to environmental change than species richness or composition, providing a better indicator of ecological change (Poisot, Guéveneux-Julien, Fortin, Gravel, \& Legendre, 2017; Tylianakis et al., 2008). For example, relationships between a host and its parasites in the tropics changed in response to habitat modification without changes in species composition (Tylianakis, Tscharntke, \& Lewis, 2007). Species relationships also play crucial roles in maintaining biodiversity and ecosystem functions at both local and regional scales (Bascompte, Jordano, \& Olesen, 2006; Gotelli, Graves, \& Rahbek, 2010; Harvey, Gounand, Ward, \& Altermatt, 2017). As a result, monitoring species composition and species relationships simultaneously might provide a better understanding of how global change affects ecosystem structure and function (McCann, 2007; Valiente-Banuet et al., 2015).

Recently, there has been an upsurge of interest in species relationships in the context of ecological networks (McCann, 2007; Morales-Castilla, Matias, Gravel, \& Araújo, 2015; Tylianakis \& Morris, 2017). This reflects important advances in the theory and methods of network analysis and its clear applicability to conservation biology and restoration ecology (Cumming, Bodin, Ernstson, \& Elmqvist, 2010; Tylianakis \& Morris, 2017). Ecological networks are composed of nodes and links, where species are nodes and the relationships between them are links. Ecological networks provide a useful conceptual framework for studying species relationships and the complexity of biological systems. However, most previous studies of species relationships have focused on spatial variation in network structures, typically along some environmental gradient (e.g., Mokross, Ryder, Côrtes, Wolfe, \& Stouffer, 2014), not how these change over time (but see CaraDonna et al., 2017; MacLeod, Genung, Ascher, \& Winfree, 2016; Petanidou, Kallimanis, Tzanopoulos, Sgardelis, \& Pantis, 2008). Without long-term baseline data, it is difficult to study how species relationship networks may vary over time (Laliberté \& Tylianakis, 2010; Poisot, Stouffer, \& Gravel, 2015). However, given the rapid change in abiotic and biotic conditions across ecosystems worldwide (Tylianakis et al., 2008), exploration of the temporal dynamics of species relationships is necessary to assess biodiversity under global change.

Plant-plant interactions (e.g., facilitation, competition), along with other factors such as environmental conditions, form the foundation of plant community assembly, on which other types of interactions (e.g., trophic interactions in food webs, pollination interactions, host-parasite interactions) build. Although plant-plant interactions are fundamental, they have received less attention than other types of ecological interactions. Part of the reason is that, although most other types of interactions can be detected by observations (e.g., pollination, predation, parasitism), plant-plant interactions are difficult to observe and thus require experiments to quantify. Conducting an adequate number of such experiments soon becomes intractable as the number of possible interactions scales with the square of the number of species.

Given that performing factorial, replicated experiments to detect how plant species interact is a time-limited process, an alternative is to examine how species associate spatially. Since the seminal work of Diamond (1975), species associations (i.e., co-occurrence) are regularly used in community ecology and biogeography as a proxy for species interactions (Cazelles, Araújo, Mouquet, \& Gravel, 2016; Gotelli, 2000). This has stimulated both controversy (Connor \& Simberloff, 1979) and new research (e.g., Gotelli \& Graves, 1996). Previous studies have suggested that biotic interactions are the main driver of local species associations (Morales-Castilla et al., 2015); species association at the local scale is possible despite or because of interactions with the other species in the community that have also passed the environmental filters. Consequently, we should be able to infer something about interactions among species based on how they co-occur locally (Araújo, Rozenfeld, Rahbek, \& Marquet, 2011; Gotelli, 2000; Harris, 2016). However, other recent studies have shown that species associations are not informative for species interactions (at least with current statistical methods; Barner, Coblentz, Hacker, \& Menge, 2018; Delalandre \& MontesinosNavarro, 2018; Freilich, Wieters, Broitman, Marquet, \& Navarrete, 2018). Here, we refer to both observed patterns of species associations and biotic interactions between species under the umbrella term "species relationships" to avoid the assumption that associations necessarily indicate interactions.

To study long-term changes in plant-plant species associations, we applied network analysis to three forest plant community types in Wisconsin, USA, sampled first in the 1950s again in the 2000s. Although most plant communities in Wisconsin have undergone 
biotic homogenization in species composition (Li \& Waller, 2015; Rogers, Rooney, Olson, \& Waller, 2008; Rooney et al., 2004), homogenization patterns of plant-plant species associations in these communities are unknown. On the one hand, homogenized species composition across locales could act to homogenize species associations as the same set of common species co-occur across most sites. On the other hand, as the species responsible for homogenizing species composition became widespread, they could form novel associations with species restricted to certain locales. Thus, differentiation of species associations could occur despite homogenization of species composition.

Here, we ask whether plant community composition and patterns of species association have changed in parallel (i.e., both homogenized or differentiated) over the last 50+ years. We also ask whether these two components of biodiversity were influenced by similar or different environmental variables in both time periods. Species associations may be inherently more labile than species composition (Poisot et al., 2017), reflecting the large number of associations present among species (with $n$ species, we have $n(n-1) / 2$ possible species associations). Therefore, we do not necessarily expect biotic homogenization in species composition to be reflected in changes in species association networks. We also hypothesize that species composition and associations are driven by the same environmental factors given the fact that associations are built on species identities. However, we do not expect these environmental factors to have the same effect over time given observed changes in environmental conditions, such as climate, across these communities. In sum, we sought to demonstrate whether species associations and species composition have similar responses to global environmental change.

\section{2 | METHODS}

\section{1 | Vegetation data}

In the 1950s, John Curtis and his students and colleagues canvassed the state of Wisconsin to find the best remaining examples of natural vegetation, then sampled $1,000+$ sites and diverse community types (Curtis, 1959). They chose only sites with no obvious disturbances and located all plots $\geq 30 \mathrm{~m}$ away from any edges. Within each site, they recorded the presence and absence of all vascular plants in each of many sampled $1-\mathrm{m}^{2}$ quadrats. The number of quadrats sampled at each site varied but was usually 20 . They were careful to archive their original data in the Plant Ecology Laboratory at the University of Wisconsin-Madison (https://www.botany.wisc.edu/ PEL/; Waller, Amatangelo, Johnson, \& Rogers, 2012). Here, we use data from three community types resurveyed since 2000 using similar methods (Supporting Information Appendix Figure S1): northern upland forests (NUF, 108 sites; Amatangelo, Fulton, Rogers, \& Waller, 2011; Rooney et al., 2004), central sands pine barrens forests (CSP, 30 sites; Li \& Waller, 2015) and southern upland forests (SUF, 128 sites; Rogers et al., 2008). These resurveyed sites showed no obvious signs of recent disturbance and were located in relatively intact habitats. Given that the original sites were not permanently marked, these are "semi-permanent" plots. The resurveys sampled two to six times as many quadrats per site as the original survey. All taxonomy was carefully synchronized between periods. To allow fair comparisons with matched sampling effort, we randomly subsampled the 2000s survey data using the same number of quadrats as used in the 1950s. Collectively, we analysed species presence/ absence data from $>5,000$ quadrats distributed among the same 266 sites in the two time periods.

\subsection{Environmental data}

We analysed environmental variables to detect drivers of plant composition and association patterns. We obtained average daily precipitation and minimal temperature for all sites from a Wisconsin climate database covering 1950-2006 (Kucharik, Serbin, Vavrus, Hopkins, \& Motew, 2010). These data are derived from an extensive network of weather stations distributed throughout the state. Downscaled data were generated via spatial interpolation. To represent each period of sampling, we averaged climate variables over two 5-year periods: 1950-1954 and 2002-2006 (cf. Ash, Givnish, \& Waller, 2017; Li \& Waller, 2017). This accounts for potential lags in species' responses and inter-annual climatic variation. We do have canopy shade data for the central sand pine barrens forests in both time periods (Li \& Waller, 2015). However, such data were not available for other vegetation types.

\section{3 | Plant association networks}

Within each vegetation type and time period, we constructed a quadrat by species matrix with rows for each quadrat (nested within a site) and columns for each species. Values in the cells of this matrix reflect the presence or absence (1/0) of that species in that quadrat. We treat the $1-\mathrm{m}^{2}$ quadrat as the sample unit here because plants that co-occur at this scale are most likely also to interact. We removed species occupying fewer than six quadrats at each period to exclude rare species and facilitate the determination of core species co-occurrence pairs. We then used this quadrat by species matrix to infer species pairs that are more or less likely to co-occur with each other in comparison to random expectations using two methods.

Our first method is based on the traditional null model approach commonly used to study species co-occurrence patterns (Gotelli, 2000). We calculated the partial $C$-score for each pair of species as $\left(c_{i}-m_{i j}\right)\left(c_{j}-m_{i j}\right)$, where $c_{i}$ and $c_{j}$ are the number of quadrat occurrences of species $i$ and $j$ and $m_{i j}$ is the number of quadrats where both species occurred. We then shuffled the cells of the quadrat by species matrix 5,000 times using the fixed-fixed randomization algorithm. We applied this null model to each site separately and then restacked the shuffled data. This constrained null model maintains row and column sums (species richness within each quadrat and species frequency across all quadrats) of the matrix while also accounting for the hierarchical structure of our dataset. In each iteration, partial $\mathrm{C}$-scores for all species pairs were computed, generating a 
null distribution from the 5,000 randomizations. This was then used to judge whether the observed $\mathrm{C}$-score reflects higher or lower cooccurrence than expected by chance. For more details, see $\mathrm{Li}$ and Waller (2016).

A recent study concluded that this null model approach has relatively low power to infer true species interactions from co-occurrence patterns and suggested using Markov networks instead (Harris, 2016). Unfortunately, current implementations of Markov networks are restricted to $\leq 20$ species (Harris, 2016), precluding their use with our dataset. A second method with power similar to Markov networks but extending to include many more species is generalized linear models (GLMs; Harris, 2016). We adopted this approach and used generalized linear mixed models (GLMMs) to account for the hierarchical structure of our dataset. In these GLMMs, we fitted Bayesian regularized logistic regression to the presence/ absence of each species (response) using the presence/absence of other species as predictors and site identity as random term. This method generates two regression coefficients and $p$-values for each species pair. We averaged these to estimate the strength of species interactions (cf. Harris, 2016). These two methods yielded qualitatively similar results. We therefore report only results from GLMMs in the main text, because these often had higher statistical power. For results from the $\mathrm{C}$-score null model, see the Supporting Information Appendix.

With the list of positive and negative association species pairs, we built one positive association metaweb and one negative association metaweb for each vegetation type and time period. Positive/ negative association indicates that a pair of species co-occur more/ less than expected by chance (based on constrained null model or GLMMs). We then built positive and negative association networks for each site from these two metawebs by sub-setting the species observed at that site. This assumes that species relationships between species do not differ across sites of the same vegetation type and time period, yielding more conservative results. To remove this assumption, one can also build an association network for each site independently. However, we lacked the power to do this given the limited number of quadrats (mostly 20) per site. Therefore, the association networks for each site in our analyses were derived from the metawebs instead of being built independently.

\section{4 | Data analysis}

\subsubsection{Changes in spatial beta diversity over time}

We calculated pairwise beta diversity in both species composition and species association networks within each vegetation type and time period using the methods proposed by Legendre and De Cáceres (2013). For pairwise beta diversity of species composition, the input is a site by species matrix, with species abundances in the cells; for species association pairwise beta diversity, the input is a site by species pairs (non-random pairs inferred via methods described in the previous subsection) matrix. In this way, we treat each nonrandom species pair as a "species" in traditional community ecology analyses (cf. Poisot et al., 2017). This approach allows us directly to compare pairwise beta diversity for species composition with beta diversity for species associations because both are calculated the same way. We compared pairwise beta diversity of each vegetation type between the 1950s and the 2000s using paired randomization tests. Lower (or higher) beta diversity in the 2000s suggests biotic homogenization (or differentiation).

Given the number of sites in NUF (108) and SUF (126), we have a large number of pairwise beta-diversity measures (5,778 and 7,875, respectively). Such large sample sizes make it possible to obtain statistically significant results that may not be biologically significant. Therefore, we also tested changes in beta diversity for each vegetation type using a distance-based permutational test for homogeneity of multivariate dispersion (PERMDISP; Anderson, Ellingsen, \& McArdle, 2006). This analysis used Bray-Curtis distances. PERMDISP calculates the distance of each site from the centroid of the ordination space and then tests whether these distances are different across groups (i.e., 1950s vs. 2000s) with permutation tests. We also use results from PERMDISP to visualize species composition and association patterns for each vegetation type and time period.

\subsubsection{Within-site changes over time}

To compare rates of change in species composition and species associations over time, we calculated beta diversity between periods within each site (i.e., a site in the 1950 s versus the same site in the 2000s), again using the method of Legendre and De Cáceres (2013). We then used a paired $t$-test to examine whether the beta-diversity values that reflect changes in species associations significantly exceed those that reflect changes in species composition (i.e., test whether species associations changed more than species composition). To confirm these results, we also applied permutational multivariate analysis of variance (PERMANOVA; Anderson, 2001) to compare changes in species composition and species associations over time.

\subsection{3 | Environmental drivers}

To understand environmental drivers for species composition and association networks, we conducted distance-based redundancy analysis (RDA) for each vegetation type and time period. We transformed the species composition and association matrix into distance matrices with the Hellinger index (Legendre \& Legendre, 2012). We used environmental variables as predictors in RDAs. To identify the most significant environmental variables, we used forward variable selection and Akaike information criterion-based statistics over 999 replicate runs for each matrix (cf. Poisot et al., 2017). The order of variable selection provides insight into the importance of environmental variables, with the earlier selected variables generally affecting species composition or the associations more. This analysis allowed us to study whether species composition and association are affected by similar sets of environmental variables in the same way and how these relationships changed over time. All analyses 
were conducted in R v.3.4.0 (R Core Team, 2017), with the package vegan (Oksanen et al., 2018) for null models and the package MCMCgImm (Hadfield, 2010) for Bayesian GLMMs.

\section{3 | RESULTS}

Across all vegetation types, most (>80\%) species pairs co-occurred randomly at both time periods as inferred from the results using Bayesian GLMMs (Table 1). Among non-random species pairs, more species pairs co-occurred negatively (7-9.5\%) than positively (4.56.7\%) across all vegetation types and time periods (Table 1).

In the NUF region, species composition, positive species associations and negative species associations all showed similar levels of dispersion in both time periods in ordination space (Figure 1; Supporting Information Appendix Figure S2). Thus, little homogenization occurred. This was confirmed by PERMDISP results (permutation test, all $p>0.25$; Table 2). However, pairwise site beta diversity calculated with methods proposed by Legendre and De Cáceres (2013) suggested homogenization in species composition and negative associations, but differentiation in positive associations (paired randomization test, both $p<0.001$; Table 2).

In the CSP region, both species composition and patterns of positive association converge in ordination space in the 2000s when compared with the 1950s (Figure 1; Supporting Information Appendix Figure S2). This suggests that these sites experienced homogenization in both species composition and positive species associations. In contrast, we observed no change in negative associations. Results from paired randomization tests on pairwise beta diversity and PERMDISP (Table 2) confirm this interpretation.

Sites in the SUF region also showed a tendency to converge in species composition and negative associations between periods (Figure 1; Supporting Information Appendix Figure S2). In contrast, positive associations tended to diverge. These results were supported by the parallel analyses of pairwise site beta diversity and PERMDISP (except negative associations; Table 2).

For all regions, shifts in beta diversity for the species association networks exceeded those for species composition ( $p=0.001$ within each site; Figure 2). Thus, it appears that species association networks have changed faster than species composition. Large turnover in species associations (positive or negative) may reflect only slight changes in species composition.

Species composition and species associations were largely influenced by the same set of environmental variables within each vegetation type and each time period (Table 3). For all sites in the 1950s, species composition and species association networks were affected by almost the same set of environmental variables. This pattern still holds in the 2000s but less so for the CSP sites. More intriguing, the importance of environmental variables on plant communities has changed over time. For example, shade was the most important for the CSP sites in the 1950s but decreased in importance by the 2000s for species composition and positive associations. Minimal temperature was the most important variable that strongly affected species composition and positive associations of the SUF sites in the 1950s but became less important by the 2000s, whereas precipitation gained importance.

\section{4 | DISCUSSION}

Few studies have quantified changes in both species composition and species relationship networks over time (Burkle, Myers, \& Belote, 2016). It takes considerable effort to construct a single interaction network, let alone networks at multiple sites over two or more time periods. We found only two empirical studies on homogenization of ecological networks. Laliberté and Tylianakis (2010) found that deforestation homogenized parasitoid-host networks in tropical areas. Although they had temporal data of parasitoid-host networks (monthly samples for 17 months), their main conclusion was derived from spatial comparisons among different land-use categories. Kehinde and Samways (2014) examined biotic homogenization of insect-flower interactions in vineyards managed under agri-environmental schemes in the Cape Floristic Region. They found no evidence of homogenization for interaction networks when comparing vineyards with natural sites.

Our study may thus be the first to explore temporal changes in beta diversity of species relationship networks. Using patterns of species co-occurrence to indicate species relationships and using a valuable, high-resolution, long-term dataset, we were able to examine parallel changes in both community composition and species

TAB LE 1 Summary of species used and species associations for each vegetation type and time period

\begin{tabular}{|c|c|c|c|c|c|c|}
\hline Type & Date & $\begin{array}{l}\text { Species used } \\
\text { (n) }\end{array}$ & $\begin{array}{l}\text { Pairs (negative association) } \\
\text { [n (\%)] }\end{array}$ & $\begin{array}{l}\text { Pairs (positive association) } \\
\text { [n (\%)] }\end{array}$ & $\begin{array}{l}\text { Pairs (random) [n } \\
\text { (\%)] }\end{array}$ & Total pairs \\
\hline NUF & $1950 \mathrm{~s}$ & 146 & $741(7)$ & $513(4.8)$ & 9,331 (88.2) & 10,585 \\
\hline CSP & $1950 \mathrm{~s}$ & 61 & $162(8.9)$ & $104(5.7)$ & $1,564(85.5)$ & 1,830 \\
\hline CSP & $2000 \mathrm{~s}$ & 55 & $125(8.4)$ & $100(6.7)$ & $1,260(84.8)$ & 1,485 \\
\hline SUF & $2000 s$ & 186 & $1,635(9.5)$ & $857(5)$ & $14,713(85.5)$ & 17,205 \\
\hline
\end{tabular}

Abbreviations: CSP: central sand plains; NUF: northern upland forests; SUF: southern upland forests. 

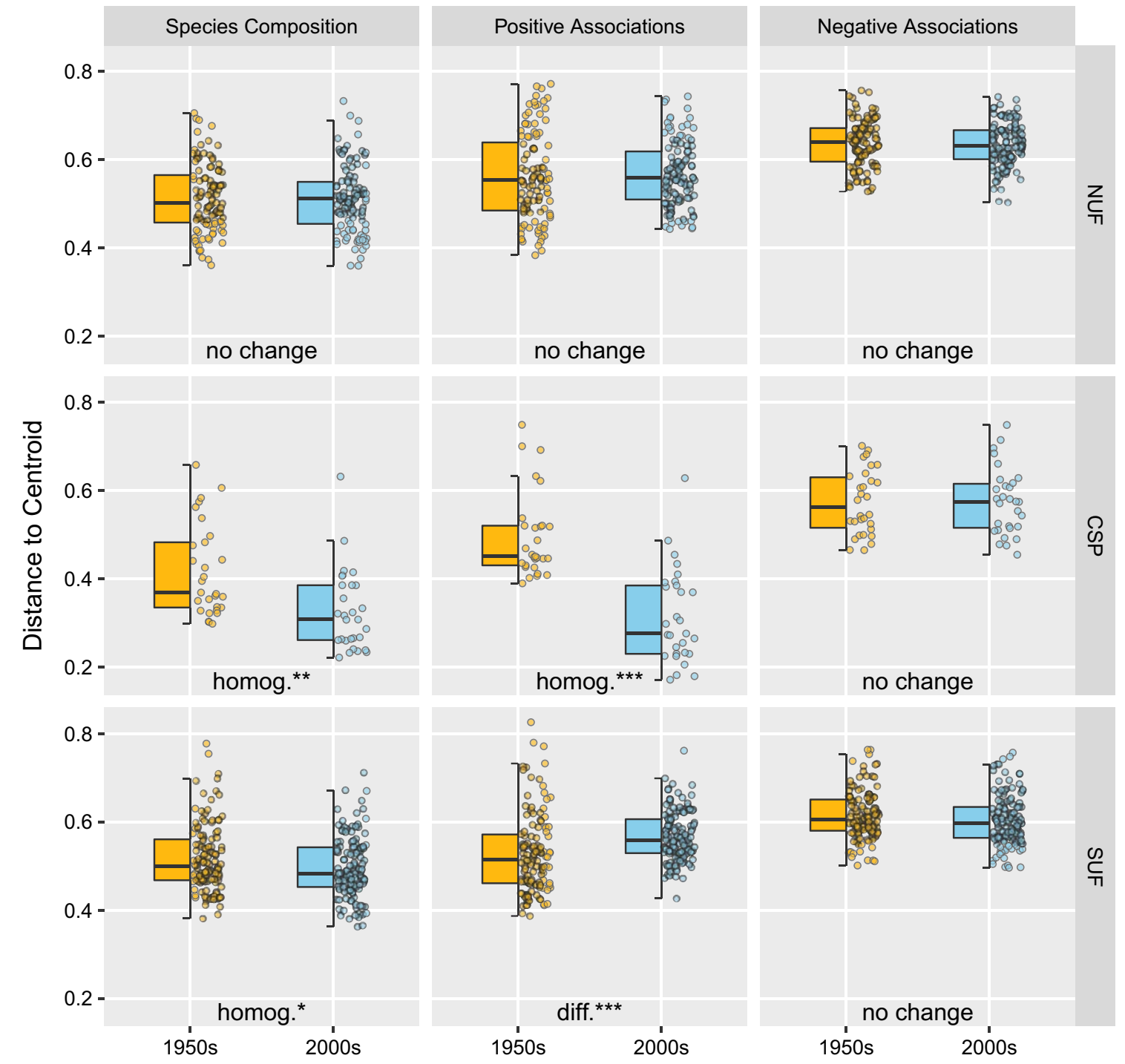

FIGURE 1 Distance to the centroid of ordinations of species composition and associations. Increases in the distance to the centroid over time indicate differentiation (diff.). Decreases in the distance to the centroid over time indicate homogenization (homog.). ${ }^{*} p<0.05$. ${ }^{* *} p<0.01{ }^{* * *} p<0.001$ [Colour figure can be viewed at wileyonlinelibrary.com]

association networks. We found that species association networks can homogenize, differentiate or show no change through time in different vegetation types regardless of the homogenization dynamics of species composition. Long-term changes in species composition and species associations thus appear to be decoupled.

In the NUF of Wisconsin, plant communities were relatively stable in terms of their species composition and species associations. Compared with other community types, NUF has a lower human population, less land-use change and less habitat fragmentation. In the present study, we found no overall changes in beta diversity of species composition and species associations when tested with PERMDISP. However, paired randomization tests on beta diversity between site pairs suggested significant homogenization in species composition, matching the conclusion (biotic impoverishment and homogenization) reached in a previous study of a subset of these sites (Rooney et al., 2004). Here, we also observed homogenization in the among-site diversity of negative species associations but significant differentiation in positive species associations. Given the large number of sites in NUF (108), the results of randomization tests might not be biologically significant despite their statistical significances. These results suggest that shifts in species composition might not occur in the same direction as shifts in species relationships.

Plant communities in the CSP historically were fire-maintained pine barrens with open canopies. However, they are succeeding into close-canopy upland forests because of fire suppression (Li \& Waller, 2015). Fire suppression has resulted in homogenization in both species composition (Li \& Waller, 2015) and functional trait composition (Li \& Waller, 2017). This probably reflects declines in habitat heterogeneity within these communities. In the 1950s, sites in the CSP had different canopy coverage, forming mosaics of burned and unburned habitats to support different plant communities. In the 2000s, however, sites were similar to each other in their canopy cover owing 


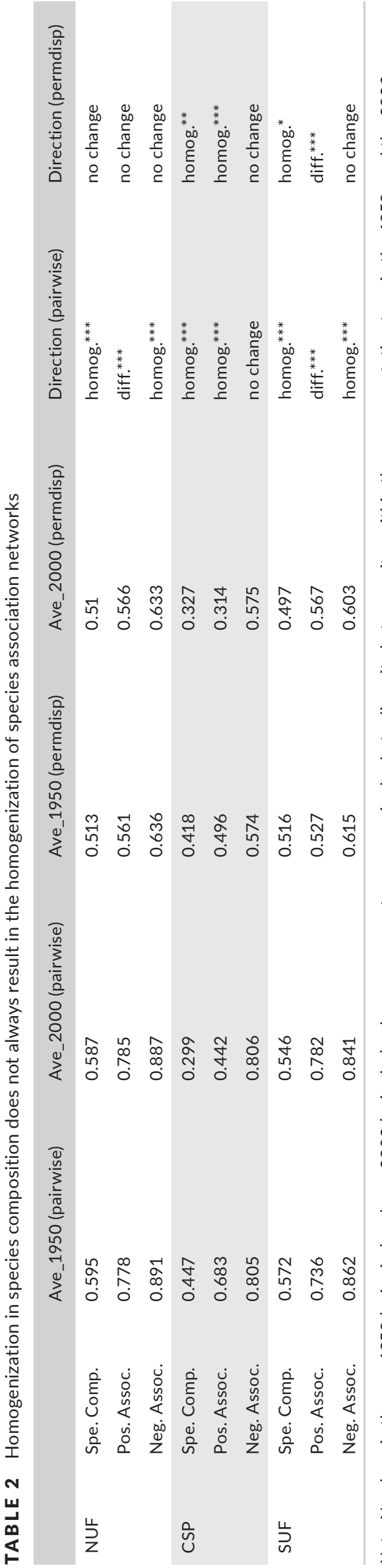

to fire suppression and succession, filtering out shade-intolerant species (Li \& Waller, 2017) and homogenizing plant communities ( $\mathrm{Li}$ \& Waller, 2015). Given these ecological changes, it is not surprising to find significant homogenization in both species composition and positive species associations in these communities.

Sites in the SUF have been affected by development and landuse changes more than any other plant community in Wisconsin (Rogers et al., 2008). Currently, most of these sites are fragmented and disturbed by nearby anthropogenic activities, including roads, development and agriculture. Previous studies suggest that habitat degradation and fragmentation tend to homogenize species composition by decreasing species diversity, which can also reduce network complexity and stability (Laliberté \& Tylianakis, 2010; Mokross et al., 2014; Tylianakis et al., 2007). However, the fact that habitat fragmentation can result in greater differences in interaction network structure (Bordes et al., 2015) suggests that network simplification (fewer nodes and/or edges) does not necessarily cause network homogenization. Networks can differ across sites if individual networks contain unique interactions even if they show a general trend towards simplification. In these SUF communities, the importance of species dispersal limitation and stochastic factors has increased, whereas the importance of species interactions has decreased over time (Li \& Waller, 2016). It is thus likely that stochastic assembly processes are forming novel sets of interactions among species even though species diversity has decreased. Indeed, we found on average 96.4 significant positive species pairs per site in the 1950 s, but only 60.3 significant positive pairs per site in the 2000 s, indicating that association networks at each site have simplified. However, both the paired randomization test on pairwise beta diversity of positive association networks and PERMDISP suggested that positive association networks in the 2000s have differentiated since the 1950 s (Table 2). Therefore, in the SUF, we found homogenization of species composition but differentiation of species positive associations.

Although changes in species associations are occurring faster than changes in species composition and appear decoupled from them, both are generally affected by similar sets of environmental variables (Table 3). For example, positive species associations and composition at all sites within each time period were affected by the same set of environmental variables. However, the importance of environmental variables for species associations and composition has changed over time for the CSP and SUF. Species associations and composition in the CSP were most affected by canopy shade in the 1950s, with climatic factors playing no role for positive associations and species composition. By the 2000s, climatic variables became more important than canopy shade. This reflects the fact that CSP forests with closed canopies show little variation in canopy cover in the 2000s. In the SUF, minimal temperature used to be more important than precipitation for species composition and positive associations; this pattern reversed in the 2000s. These results suggest that species associations and composition are generally affected by a similar set of environmental variables. As global environmental changes accelerate, the relative importance of environmental variables may change further, contributing to the emergence of novel 
FIGURE 2 Beta diversity of species composition and association of the same site over time. Each point represents the beta diversity of the same site between the 1950s and the 2000s. Beta diversity of one indicates that the species composition or species association in the 1950s and the 2000s were totally different, whereas beta diversity of zero indicates no changes in a site over time. Turnover in species relationships appears to be much greater than the turnover in species composition [Colour figure can be viewed at wileyonlinelibrary.com]

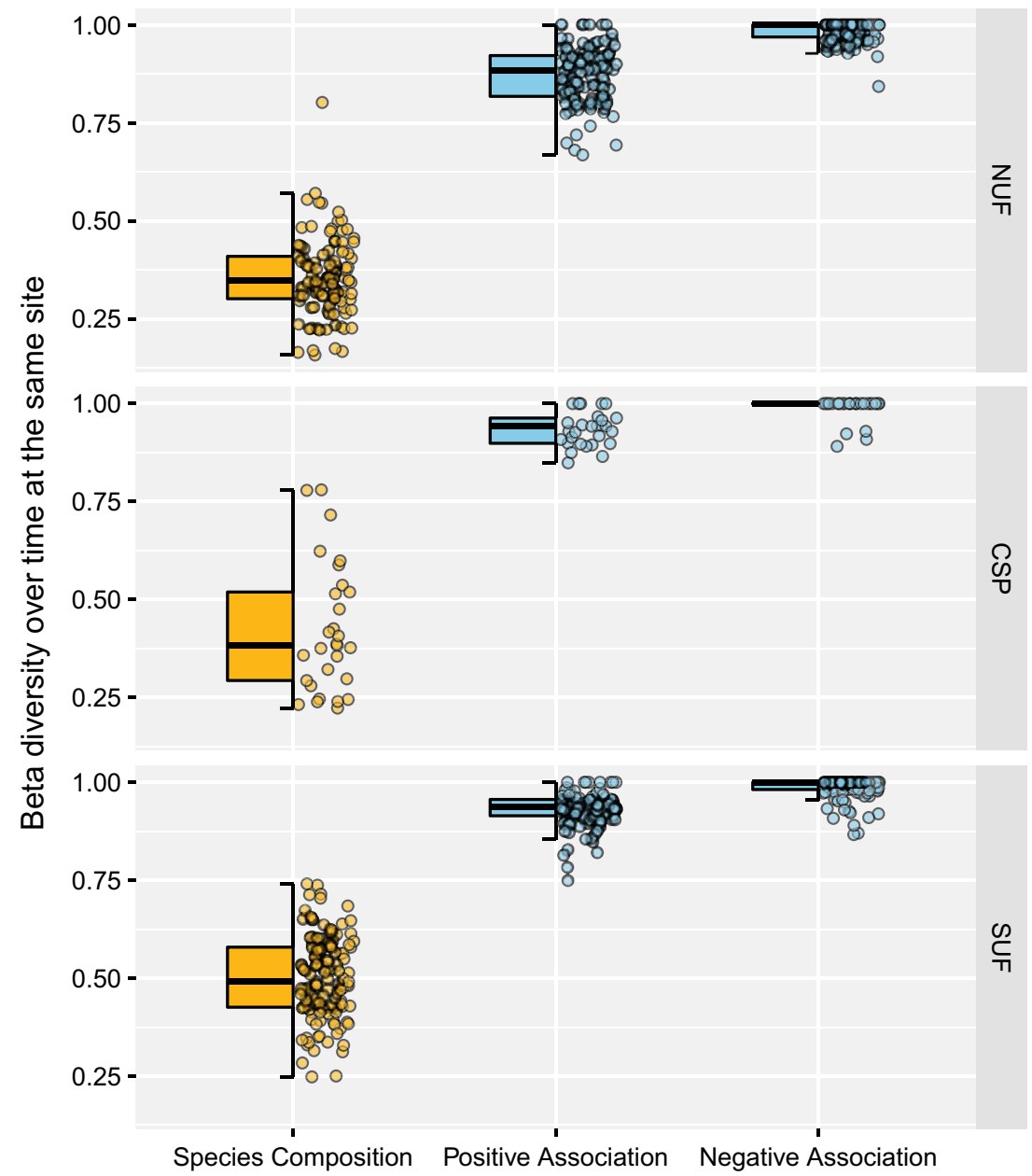

TABLE 3 Selected environmental variables for species composition and species associations

Note. Numbers are the order in which variables are selected. Dash (-) means that the environmental variable is not available. Blank cells mean that these variables are dropped out. Abbreviations: Neg. Assoc.: negative association; Pos. Assoc.: positive association; Spe. Comp.: species composition. 
arrays of species and consequent species interactions (Blois et al., 2013; Milazzo et al., 2013).

Species association (co-occurrence) patterns have commonly been used to represent species interactions, because it is intractable to quantify interactions among hundreds of plant species. Species associations may give false-positive (hypothesized links that do not exist in the real system) interactions between species and may not detect all real interactions (Barner et al., 2018; Delalandre \& Montesinos-Navarro, 2018; Freilich et al., 2018). However, our main goal is to study broad patterns of community structure and dynamics rather than to pinpoint exact interactions between particular species pairs. For this purpose, species spatial association networks are a necessary and useful proxy (Freilich et al., 2018), because they can provide valuable information regarding the net output of direct and indirect effects among multiple plant species (rather than exact pairwise interactions; Delalandre \& Montesinos-Navarro, 2018). Co-occurrence networks may also serve to predict overall community responses to disturbance (Tulloch, Chadès, \& Lindenmayer, 2018). To reduce the potential for bias, we studied species association patterns at a fine spatial scale $\left(1 \mathrm{~m}^{2}\right)$ and used statistical methods (Bayesian GLMMs) that have relatively high power for detecting species interactions (Harris, 2016). Furthermore, we used a common null model approach and reported these results in the Supporting Information Appendix. Given that both methods provide quantitatively similar results and reach the same conclusion, our conclusion that changes in species associations and species composition are decoupled is likely to be robust. Consequently, our results from species association networks may also hold for species interaction networks.

An assumption made in this study is that species associations within each vegetation type and time period remain consistent across sites. In reality, associations between species can vary through space and time (Poisot et al., 2015). Given that we lacked the data to analyse how species associations may have differed over sites, we pooled data across sites to gain insights into the average nature of species associations within each community. This makes our results conservative, because accounting for variation in species associations over sites could show only greater variation in network structure, strengthening our conclusion that temporal changes in species associations and composition are decoupled.

Our results suggest that species relationships may not be experiencing a general trend towards homogenization, because novel relationships may be forming in response to rapid global change. This raises important questions about how such changes in species relationships might affect community stability, ecosystem services and species co-evolution. Studies of beta diversity in species relationships remain in their infancy (Burkle et al., 2016). Given the importance of species relationships and their potential unpredictable relationship with species composition, future empirical and theoretical research that investigates patterns, causes and consequences of changes in beta diversity of relationship networks are needed.

\section{5 | BIOSKETCH}

DAIJIANG LI is a post-doctoral researcher at the Department of Wildlife Ecology \& Conservation, University of Florida. His research interests cover community ecology, functional and phylogenetic diversity, biological invasions, global change biology and ecological modelling.

\section{DATA ACCESSIBILITY}

The data used in this study have been deposited to figshare (https://figshare.com/s/5a98a69a66f22644361e) with https://doi. org/10.6084/m9.figshare.6771938.

\section{ORCID}

Daijiang Li (iD http://orcid.org/0000-0002-0925-3421

Timothée Poisot (iD http://orcid.org/0000-0002-0735-5184

Benjamin Baiser (iD http://orcid.org/0000-0002-3573-1183

\section{REFERENCES}

Amatangelo, K. L., Fulton, M. R., Rogers, D. A., \& Waller, D. M. (2011). Converging forest community composition along an edaphic gradient threatens landscape-level diversity. Diversity and Distributions, 17, 201-213. https://doi.org/10.1111/j.1472-4642.2010.00730.x

Anderson, M. J. (2001). A new method for non-parametric multivariate analysis of variance. Austral Ecology, 26, 32-46.

Anderson, M. J., Ellingsen, K. E., \& McArdle, B. H. (2006). Multivariate dispersion as a measure of beta diversity. Ecology Letters, 9, 683-693. https://doi.org/10.1111/j.1461-0248.2006.00926.x

Araújo, M. B., Rozenfeld, A., Rahbek, C., \& Marquet, P. A. (2011). Using species co-occurrence networks to assess the impacts of climate change. Ecography, 34, 897-908. https://doi. org/10.1111/j.1600-0587.2011.06919.x

Ash, J. D., Givnish, T. J., \& Waller, D. M. (2017). Tracking lags in historical plant species' shifts in relation to regional climate change. Global Change Biology, 23, 1305-1315. https://doi.org/10.1111/gcb.13429

Baiser, B., Olden, J. D., Record, S., Lockwood, J. L., \& McKinney, M. L. (2012). Pattern and process of biotic homogenization in the new Pangaea. Proceedings of the Royal Society B: Biological Sciences, 279, 4772-4777.

Barner, A. K., Coblentz, K. E., Hacker, S. D., \& Menge, B. A. (2018). Fundamental contradictions among observational and experimental estimates of non-trophic species interactions. Ecology, 99, 557-566. https://doi.org/10.1002/ecy.2133

Bascompte, J., Jordano, P., \& Olesen, J. M. (2006). Asymmetric coevolutionary networks facilitate biodiversity maintenance. Science, 312, 431-433. https://doi.org/10.1126/science.1123412

Blois, J. L., Zarnetske, P. L., Fitzpatrick, M. C., \& Finnegan, S. (2013). Climate change and the past, present, and future of biotic interactions. Science, 341, 499-504. https://doi.org/10.1126/science.1237184

Bordes, F., Morand, S., Pilosof, S., Claude, J., Krasnov, B. R., Cosson, J.-F., ... Blasdell, K. (2015). Habitat fragmentation alters the properties of a host-parasite network: Rodents and their helminths in SouthEast Asia. Journal of Animal Ecology, 84, 1253-1263. https://doi. org/10.1111/1365-2656.12368

Burkle, L. A., Myers, J. A., \& Belote, R. T. (2016). The beta-diversity of species interactions: Untangling the drivers of geographic variation in plant-pollinator diversity and function across scales. 
American Journal of Botany, 103, 118-128. https://doi.org/10.3732/ ajb.1500079

CaraDonna, P. J., Petry, W. K., Brennan, R. M., Cunningham, J. L., Bronstein, J. L., Waser, N. M., \& Sanders, N. J. (2017). Interaction rewiring and the rapid turnover of plant-pollinator networks. Ecology Letters, 20, 385-394. https://doi.org/10.1111/ele.12740

Cazelles, K., Araújo, M. B., Mouquet, N., \& Gravel, D. (2016). A theory for species co-occurrence in interaction networks. Theoretical Ecology, 9 , 39-48. https://doi.org/10.1007/s12080-015-0281-9

Connor, E. F., \& Simberloff, D. (1979). The assembly of species communities: Chance or competition? Ecology, 60, 1132-1140. https://doi. org/10.2307/1936961

Cumming, G. S., Bodin, Ö., Ernstson, H., \& Elmqvist, T. (2010). Network analysis in conservation biogeography: Challenges and opportunities. Diversity and Distributions, 16, 414-425. https://doi. org/10.1111/j.1472-4642.2010.00651.x

Curtis, J. T. (1959). The vegetation of Wisconsin: An ordination of plant communities. Madison, WI: University of Wisconsin Press.

de Solar, R. R. C., Barlow, J., Ferreira, J., Berenguer, E., Lees, A. C., Thompson, J. R., ... Gardner, T. A. (2015). How pervasive is biotic homogenization in human-modified tropical forest landscapes? Ecology Letters, 18, 1108-1118. https://doi.org/10.1111/ele.12494

Delalandre, L., \& Montesinos-Navarro, A. (2018). Can co-occurrence networks predict plant-plant interactions in a semi-arid gypsum community? Perspectives in Plant Ecology, Evolution and Systematics, 31, 36-43. https://doi.org/10.1016/j.ppees.2018.01.001

Diamond, J. M. (1975). Assembly of species communities. Ecology and Evolution of Communities, 342-444.

Freilich, M. A., Wieters, E., Broitman, B., Marquet, P. A., \& Navarrete, S. A. (2018). Species co-occurrence networks: Can they reveal trophic and non-trophic interactions in ecological communities? Ecology, 99, 690-699. https://doi.org/10.1002/ecy.2142

Gotelli, N. J. (2000). Null model analysis of species co-occurrence patterns. Ecology, 81, 2606-2621. https://doi. org/10.1890/0012-9658(2000)081[2606:NMAOSC]2.0.CO;2

Gotelli, N. J., \& Graves, G. R. (1996). Null models in ecology. Washington, DC: Smithsonian Institution.

Gotelli, N. J., Graves, G. R., \& Rahbek, C. (2010). Macroecological signals of species interactions in the Danish avifauna. Proceedings of the National Academy of Sciences of the USA, 107, 5030-5035. https://doi. org/10.1073/pnas.0914089107

Hadfield, J. D. (2010). MCMC methods for multi-response generalized linear mixed models: The MCMCgImm R package. Journal of Statistical Software, 33, 1-22.

Harley, C. D. (2011). Climate change, keystone predation, and biodiversity loss. Science, 334, 1124-1127. https://doi.org/10.1126/ science.1210199

Harris, D. J. (2016). Inferring species interactions from co-occurrence data with Markov networks. Ecology, 97, 3308-3314. https://doi. org/10.1002/ecy.1605

Harvey, E., Gounand, I., Ward, C. L., \& Altermatt, F. (2017). Bridging ecology and conservation: From ecological networks to ecosystem function. Journal of Applied Ecology, 54, 371-379. https://doi. org/10.1111/1365-2664.12769

Hegland, S. J., Nielsen, A., Lázaro, A., Bjerknes, A.-L., \& Totland, $\varnothing$. (2009). How does climate warming affect plant-pollinator interactions? Ecology Letters, 12, 184-195. https://doi. org/10.1111/j.1461-0248.2008.01269.x

Hobbs, R. J., Higgs, E., \& Harris, J. A. (2009). Novel ecosystems: Implications for conservation and restoration. Trends in Ecology and Evolution, 24, 599-605. https://doi.org/10.1016/j.tree.2009.05.012

Kehinde, T., \& Samways, M. J. (2014). Effects of vineyard management on biotic homogenization of insect-flower interaction networks in the cape floristic region biodiversity hotspot. Journal of Insect Conservation, 18, 469-477. https://doi.org/10.1007/ s10841-014-9659-z
Kucharik, C. J., Serbin, S. P., Vavrus, S., Hopkins, E. J., \& Motew, M. M. (2010). Patterns of climate change across Wisconsin from 1950 to 2006. Physical Geography, 31, 1-28. https://doi. org/10.2747/0272-3646.31.1.1

Laliberté, E., \& Tylianakis, J. M. (2010). Deforestation homogenizes tropical parasitoid-host networks. Ecology, 91, 1740-1747. https://doi. org/10.1890/09-1328.1

Legendre, P., \& De Cáceres, M. (2013). Beta diversity as the variance of community data: Dissimilarity coefficients and partitioning. Ecology Letters, 16, 951-963. https://doi.org/10.1111/ele.12141

Legendre, P., \& Legendre, L. F. (2012). Numerical ecology. Amsterdam, The Netherlands: Elsevier.

Li, D., \& Waller, D. M. (2015). Drivers of observed biotic homogenization in pine barrens of central Wisconsin. Ecology, 96, 1030-1041. https:// doi.org/10.1890/14-0893.1

Li, D., \& Waller, D. M. (2016). Long-term shifts in the patterns and underlying processes of plant associations in Wisconsin forests. Global Ecology and Biogeography, 25, 516-526. https://doi.org/10.1111/ geb.12432

Li, D., \& Waller, D. M. (2017). Fire exclusion and climate change interact to affect long-term changes in the functional composition of plant communities. Diversity and Distributions, 23, 496-506. https://doi. org/10.1111/ddi.12542

Loreau, M., Mouquet, N., \& Gonzalez, A. (2003). Biodiversity as spatial insurance in heterogeneous landscapes. Proceedings of the National Academy of Sciences of the USA, 100, 12765-12770. https://doi. org/10.1073/pnas.2235465100

MacLeod, M., Genung, M. A., Ascher, J. S., \& Winfree, R. (2016). Measuring partner choice in plant-pollinator networks: Using null models to separate rewiring and fidelity from chance. Ecology, 97, 2925-2931. https://doi.org/10.1002/ecy.1574

McCann, K. (2007). Protecting biostructure. Nature, 446, 29-29. https:// doi.org/10.1038/446029a

McKinney, M. L., \& Lockwood, J. L. (1999). Biotic homogenization: A few winners replacing many losers in the next mass extinction. Trends in Ecology and Evolution, 14, 450-453. https://doi.org/10.1016/ S0169-5347(99)01679-1

Milazzo, M., Mirto, S., Domenici, P., \& Gristina, M. (2013). Climate change exacerbates interspecific interactions in sympatric coastal fishes. Journal of Animal Ecology, 82, 468-477. https://doi. org/10.1111/j.1365-2656.2012.02034.x

Mokross, K., Ryder, T. B., Côrtes, M. C., Wolfe, J. D., \& Stouffer, P. C. (2014) Decay of interspecific avian flock networks along a disturbance gradient in Amazonia. Proceedings of the Royal Society B: Biological Sciences, 281, 20132599.

Morales-Castilla, I., Matias, M. G., Gravel, D., \& Araújo, M. B. (2015). Inferring biotic interactions from proxies. Trends in Ecology and Evolution, 30, 347-356. https://doi.org/10.1016/j.tree.2015.03.014

Oksanen, J., Blanchet, F. G., Friendly, M., Kindt, R., Legendre, P., McGlinn, D., ... Wagner, H. (2018). Vegan: Community ecology package. R package version 2.5-2. https://CRAN.R-project.org/package=vegan

Olden, J. D., Comte, L., \& Giam, X. (2018). The Homogocene: A research prospectus for the study of biotic homogenisation. NeoBiota, 37, 23. https://doi.org/10.3897/neobiota.37.22552

Olden, J. D., \& Poff, N. L. (2003). Toward a mechanistic understanding and prediction of biotic homogenization. The American Naturalist, 162, 442-460. https://doi.org/10.1086/378212

Olden, J. D., Poff, N. L., Douglas, M. R., Douglas, M. E., \& Fausch, K. D. (2004). Ecological and evolutionary consequences of biotic homogenization. Trends in Ecology and Evolution, 19, 18-24. https://doi. org/10.1016/j.tree.2003.09.010

Petanidou, T., Kallimanis, A. S., Tzanopoulos, J., Sgardelis, S. P., \& Pantis, J. D. (2008). Long-term observation of a pollination network: Fluctuation in species and interactions, relative invariance of network structure and implications for estimates of specialization. Ecology Letters, 11 564-575. https://doi.org/10.1111/j.1461-0248.2008.01170.x 
Poisot, T., Guéveneux-Julien, C., Fortin, M.-J., Gravel, D., \& Legendre, P. (2017). Hosts, parasites and their interactions respond to different climatic variables. Global Ecology and Biogeography, 26, 942-951. https://doi.org/10.1111/geb.12602

Poisot, T., Stouffer, D. B., \& Gravel, D. (2015). Beyond species: Why ecological interaction networks vary through space and time. Oikos, 124, 243-251. https://doi.org/10.1111/oik.01719

R Core Team. (2017). R: A language and environment for statistical computing. Vienna, Austria: R Foundation for Statistical Computing.

Rockwell, R. F., Gormezano, L. J., \& Koons, D. N. (2011). Trophic matches and mismatches: Can polar bears reduce the abundance of nesting snow geese in western Hudson Bay? Oikos, 120, 696-709. https:// doi.org/10.1111/j.1600-0706.2010.18837.x

Rogers, D. A., Rooney, T. P., Olson, D., \& Waller, D. M. (2008). Shifts in southern Wisconsin forest canopy and understory richness, composition, and heterogeneity. Ecology, 89, 2482-2492. https://doi. org/10.1890/07-1129.1

Rooney, T. P., Wiegmann, S. M., Rogers, D. A., \& Waller, D. M. (2004). Biotic impoverishment and homogenization in unfragmented forest understory communities. Conservation Biology, 18, 787-798. https:// doi.org/10.1111/j.1523-1739.2004.00515.x

Sala, O. E., Chapin, F. S., Armesto, J. J., Berlow, E., Bloomfield, J., Dirzo, R., .... Leemans, R. (2000). Global biodiversity scenarios for the year 2100. Science, 287, 1770-1774.

Tulloch, A. I., Chadès, I., \& Lindenmayer, D. B. (2018). Species co-occurrence analysis predicts management outcomes for multiple threats. Nature Ecology \& Evolution, 2, 465-474. https://doi.org/10.1038/ s41559-017-0457-3

Tylianakis, J. M., Didham, R. K., Bascompte, J., \& Wardle, D. A. (2008). Global change and species interactions in terrestrial ecosystems. Ecology Letters, 11, 1351-1363. https://doi. org/10.1111/j.1461-0248.2008.01250.x

Tylianakis, J. M., \& Morris, R. J. (2017). Ecological networks across environmental gradients. Annual Review of Ecology,
Evolution, and Systematics, 48, 25-48. https://doi.org/10.1146/ annurev-ecolsys-110316-022821

Tylianakis, J. M., Tscharntke, T., \& Lewis, O. T. (2007). Habitat modification alters the structure of tropical host-parasitoid food webs. Nature, 445, 202-205. https://doi.org/10.1038/nature05429

Valiente-Banuet, A., Aizen, M. A., Alcántara, J. M., Arroyo, J., Cocucci, A., Galetti, M., ... Jordano, P. (2015). Beyond species loss: The extinction of ecological interactions in a changing world. Functional Ecology, 29, 299-307. https://doi.org/10.1111/1365-2435.12356

Vitousek, P. M., Mooney, H. A., Lubchenco, J., \& Melillo, J. M. (1997). Human domination of earth's ecosystems. Science, 277, 494-499. https://doi.org/10.1126/science.277.5325.494

Waller, D. M., Amatangelo, K. L., Johnson, S., \& Rogers, D. A. (2012). Wisconsin vegetation database - plant community survey and resurvey data from the Wisconsin plant ecology laboratory. Biodiversity \& Ecology, 4, 255-264. https://doi.org/10.7809/b-e.00082

\section{SUPPORTING INFORMATION}

Additional supporting information may be found online in the Supporting Information section at the end of the article.

How to cite this article: Li D, Poisot T, Waller DM, Baiser B. Homogenization of species composition and species association networks are decoupled. Global Ecol Biogeogr. 2018;27:1481-1491. https://doi.org/10.1111/geb.12825 